\title{
Konsistensi Sikap Petani terhadap Kemampuan Mengakses Informasi Teknologi Pertanian di Kabupaten Pacitan
}

Rika Jayanti Malik $^{12 *}$, Sunarru Samsi Hariadi ${ }^{1}$, Roso Witjaksono ${ }^{1}$, Paulus Wiryono Priyotamtama ${ }^{1}$ ${ }^{1}$ Program Studi Penyuluhan dan Komunikasi Pembangunan, Sekolah Pascasarjana, Universitas Gadjah Mada

${ }^{2}$ Balai Pengkajian Teknologi Pertanian Banten

\begin{tabular}{l}
\hline \multicolumn{1}{c}{ ARTIKEL INFO } \\
\hline Sejarah artikel \\
Diterima $12 / 11 / 2020$ \\
Diterima dalam bentuk revisi 05/12/2020 \\
Diterima dan disetujui 08/12/2020 \\
Tersedia online 23/12/2020 \\
\hline Kata kunci \\
Akses \\
Konsistensi sikap \\
Petani \\
\hline
\end{tabular}

\begin{abstract}
ABSTRAK
Sikap petani adalah respon petani berupa pernyataan setuju atau tidak setuju terhadap objek tertentu. Tujuan penelitian ini yaitu untuk mendeskripsikan sikap petani terhadap informasi teknologi pertanian yang didiseminikasi Taman Teknologi Pertanian (TTP) Pringkuku dan pengaruhnya terhadap kemampuannya memperoleh informasi. Penelitian di Kabupaten Pacitan pada Februari-April 2020 dengan pendekatan kuantitatif. Penelitian melibatkan 167 orang petani yang pernah belajar di TTP Pringkuku dan dipilih secara acak. Teknik pengambilan data melalui wawancara langsung kepada responden dengan menggunakan kuesioner tertutup. Keseluruhan item variabel sikap dan kemampuan petani mengakses informasi teknologi pertanian dalam kuesioner valid dan reliabel dengan nilai croncbach Alfa > 0,70 . Data penelitian dianalisis secara deskriptif menggunakan uji regresi linear sederhana. Hasilnya (1) rerata capaian sikap petani $59,96 \%$ menunjukkan bahwa sikap petani ragu-ragu terhadap informasi teknologi pertanian yang didiseminasikan TTP Pingkuku baik di kebun percontohan maupun melalui media baru. Keraguan tersebut didasarkan pada pertimbangan biaya dan kompleksitas inovasi; (2) petani mengalami inkonsistensi sikap. Capaian ranah kognitif 61,63\% menunjukkan petani setuju dan afektif senang $(66,20 \%)$ tetapi konatifnya ragu-ragu $(51,50 \%)$ terhadap informasi teknologi pertanian; dan (3) sikap petani signifikan memengaruhi kemampuannya untuk mengakses informasi teknologi pertanian. Semakin petani setuju terhadap informasi teknologi pertanian maka semakin meningkat kemampuannya untuk mencari dan memperoleh informasi terkait teknologi pertanian.
\end{abstract}

(C) 2020 Politeknik Pembangunan Pertanian Manokwari 


\section{ABSTRACT}

The farmer's attitude is farmer's response be in the form of a statement agree or disagree to a certain object. The study described the farmer's attitude towards agricultural technology information disseminated by the Pringkuku Agricultural Technology Park (TTP) and the effect toward farmer's ability to access information. The research at Pacitan Regency during Februari-April 2020 and used a quantitative approach. Respondent were 167 farmers who had studied at TTP Pringkuku and were randomly selected. The technique of collecting data through direct interview used a closed questionnaire. Attitude and farmer's ability to access agricultural technology information variabels had valid and reliable with a Croncbach Alfa value > 0.70. Data were analyzed descriptively

\section{PENDAHULUAN}

Manusia tidak terlepas dari informasi dan komunikasi dalam proses kehidupan sosialnya. Perkembangan Teknologi Informasi dan Komunikasi (TIK) nyatanya berdampak bagi perubahan perilaku manusia untuk mencari dan memperoleh informasi. Kemajuan TIK memberikan dampak bagi pola hidup dan perilaku manusia. Hadirnya media sosial memfasilitasi antar individu lebih mudah mengakses informasi dan berkomunikasi tanpa batas waktu, jarak dan ruang (Syawqi, 2017).

Kemudahan tanpa batas yang ditawarkan media baru belum optimal dimanfaatkan pelaku utama pertanian. Kemkominfo (2015) melaporkan bahwa kemampuan petani dalam memanfaatkan TIK untuk pengembangan usaha masih rendah. Rendahnya kemampuan tersebut disebabkan faktor internal dan eksternal petani. Faktor internal yang menghambat petani memanfaatkan TIK dalam pengembangan usaha yaitu (1) kepemilikan smartphone used simple linear regression test. The results were (1) average of achievement farmer's attitude $59.96 \%$, showed that farmer's attitude had doubt about agricultural technology information disseminated by TTP Pingkuku both in demonstration farm and through new media. This doubt based on considerations of innovation's cost and complexity; (2) farmer's attitude was inconsistencies. Achievement of cognitive $61.63 \%$ showed that farmers agree and the affective were pleased (66.20\%) but they were doubt (51.50\%) about agricultural technology information; and (3) farmer's attitude significantly affected their ability to access agricultural technology information.

sebatas untuk komunikasi biasa dan belum menjadi sarana dalam mengakses informasi yang dibutuhkan, (2) petani merasa tidak butuh smartphone, dan (3) petani belum paham cara mengoperasikan smarthpone. Faktor eksternal yang menghambat petani memanfaatkan TIK terletak pada keterbatasan infrastruktur dan sinyal.

Kesenjangan antara perkembangan TIK dan kemampuan petani memanfaatkannya menarik diamati, karena hasil-hasil penelitian masif disebarkan baik secara langsung di lapang maupun melalui media baru. Kementerian Pertanian melalui Badan Litbang Pertanian kurun waktu 2015-2018 telah menginisiasi lahirnya Taman Teknologi Pertanian (TTP) di beberapa kota/kabupaten seluruh Indonesia. Hadirnya TTP mendorong tumbuhnya perekonomian baru bagi masyarakat yang berasal dari bidang pertanian (Mulyandari dkk, 2016).

Target pembangunan TTP tiap tahunnya berubah dan realisasinyapun tidak selalu sesuai 
harapan. Laporan Badan Litbang Pertanian (2018) menyampaikan bahwa tahun 2015 dan 2016 target pembangunan terpenuhi yaitu 16 dan 10 TTP. Tahun 2017 target tidak terpenuhi karena menyelesaikan pembangunan TTP tahun-tahun sebelumnya, sedangkan tahun 2018 terealisasi 5 TTP dari yang ditargetkan 30 TTP. Pacitan merupakan salah satu kabupaten yang mendapatkan program TTP pada tahun 2015. Lokasi TTP berada di Desa Pringkuku Kecamatan Pringkuku yang lahirnya hasil kerjasama Balai Pengkajian Teknologi (BPTP) Jawa Timur dengan Pemerintah Kabupaten (Pemkab) Pacitan. BPTP Jawa Timur merupakan Unit Kerja/Unit Pelaksana Teknis Badang Litbang Pertanian, sehingga keberadaanya merupakan perpanjangan tangan dari pemerintah pusat.

TTP Pringkuku mendiseminasikan informasi teknologi (Infotek) pertanian melalui kebun percontohan, website, facebook, yotube, dan whatsapp. Upaya TTP Pringkuku memanfaatkan TIK selaras dengan harapan Kementerian Pertanian tentang digital farming. Harapannya, petani dan keluarganya lebih mudah mengakses informasi baik secara langsung maupun melalui media baru untuk memenuhi kebutuhan informasi terkait usaha taninya. Efektivitas TTP Pringkuku sebagai sumber informasi kemudian perlu disandingkan dengan evaluasi sikap petani terhadap infotek pertanian yang diterimanya baik dari kebun percontohan maupun media baru. Sikap petani penting dianalisa karena konsistensi sikap cenderung memengaruhi perilakunya dalam mencari dan mengakses infotek pertanian dari TTP Pringkuku.

\section{METODE}

Penelitian dilakukan di Kabupaten Pacitan pada Bulan Februari - April 2020 menggunakan metode kuantitatif. Responden penelitian adalah 167 orang petani yang pernah belajar di TTP Pringkuku dan diambil secara acak. Teknik pengambilan data melalui survei (wawancara) petani menggunakan kuesioner tertutup. Data primer yang dihimpun meliputi identitas responden, sikap responden, dan kemampuan responden untuk mengakses infotek pertanian dari TTP Pringkuku. Kuesioner penelitian memenuhi syarat validitas dan reliabilitas. Keseluruhan item terkait sikap dan kemampuan petani mengakses infotek pertanian valid dengan nilai croncbach Alfa > 0,70. Nilai croncbach Alfa variabel sikap 0,859 dan nilai croncbach Alfa variabel akses 0,901. Analisa data secara diskriptif menggunakan statistik parametrik dan untuk melihat pengaruh antar variabel dianalisa melalui uji regresi linear sederhana melalui program SPSS 23.

Syarat uji statistik parametrik telah terpenuhi karena (1) data ordinal telah diubah menjadi data interval melalui metode summated ranking (skala Likert), (2) sampel dipilih secara acak, (3) data berdistribusi normal ditunjukkan oleh uji KolmogrovSmirnov (0,065 > 0,05), dan (4) jumlah sampel besar (> 30 orang). Konsistensi sikap dan kemampuan petani mengakses infotek pertanian dianalisa dengan melihat presentase capaian dan kategori di tiap indikatornya. Ranah kognitif, afektif, dan konatif merupakan indikator sikap. Adapun indikator kemampuan petani mengakses infotek pertanian dibedakan 
berdasarkan medium informasinya yaitu kebun

capaian variabel ditampilkan pada tabel 1 .

percontohan dan media baru. Kategori dan

Tabel 1. Kategori dan Capaian Variabel Sikap dan Kemampuan Petani Mengakses Infotek Pertanian TTP Pringkuku

\begin{tabular}{|c|c|c|c|c|c|c|}
\hline \multirow[t]{2}{*}{ No } & \multirow{2}{*}{ Variabel } & \multicolumn{5}{|c|}{ Kategori Skor } \\
\hline & & $0-\leq 20$ & $>20-\leq 40$ & $>40-\leq 60$ & $>60-\leq 80$ & $>80-\leq 100$ \\
\hline 1. & Sikap & $\begin{array}{l}\text { Sangat tidak } \\
\text { setuju }\end{array}$ & Tidak setuju & Ragu-ragu & Setuju & Sangat setuju \\
\hline 2. & $\begin{array}{l}\text { Kemampuan } \\
\text { akses } \\
\text { informasi }\end{array}$ & $\begin{array}{l}\text { Sangat tidak } \\
\text { mampu } \\
\text { (sangat } \\
\text { rendah) }\end{array}$ & $\begin{array}{l}\text { Tidak mampu } \\
\text { (rendah) }\end{array}$ & $\begin{array}{l}\text { Cukup } \\
\text { Mampu } \\
\text { (Ragu-ragu) }\end{array}$ & $\begin{array}{l}\text { Mampu } \\
\text { (tinggi) }\end{array}$ & $\begin{array}{l}\text { Sangat } \\
\text { Mampu } \\
\text { (sangat } \\
\text { tinggi) }\end{array}$ \\
\hline
\end{tabular}

\section{HASIL DAN PEMBAHASAN}

Taman Teknologi Pertanian Pringkuku memberikan kesempatan masyarakat Kabupaten Pacitan untuk mengakses infotek pertanian di kebun percontohan dan website/media sosial. Whatsapp adalah media baru yang aktif dimanfaatkan TTP Pringkuku hingga penelitian ini berlangsung. Website dengan laman ttppacitan.com dan facebook cenderung tidak melakukan pembaharuan informasi. Inovasi yang didiseminasikan TTP
Pringkuku meliputi teknologi budidaya padi, teknologi budidaya jeruk, teknologi budidaya sapi potong, teknologi pengolahan hasil dan limbah pertanian. Petani yang mengunjungi/belajar di TTP Pringkuku berkesempatan mengakses informasi yang dibutuhkan untuk usaha taninya. Karakteristik petani yang pernah mengakses infotek pertanian TTP Pringkuku ditampilkan pada Tabel 2.

Tabel 2. Karakteristik Petani yang Mengunjungi/Belajar di TTP Pringkuku

\begin{tabular}{|c|c|c|}
\hline No. & Karakteristik Petani & Keterangan \\
\hline 1. & Rata-rata umur (tahun) & 43,11 \\
\hline 2. & Rata-rata pendidikan (tahun) & 10,42 \\
\hline \multirow[t]{3}{*}{3.} & Jenis kelamin: & \\
\hline & a. Laki-laki (\%) & 63,47 \\
\hline & b. Perempuan $(\%)$ & 36,53 \\
\hline 4. & Rata-rata lama tergabung dalam kelompok (tahun) & 10,37 \\
\hline 5. & Rata-rata lama usaha tani (tahun) & 23,22 \\
\hline \multirow[t]{3}{*}{6.} & Mata pencaharian: & \\
\hline & a. Bidang pertanian (\%) & 44,91 \\
\hline & b. Non pertanian $(\%)$ & 55,09 \\
\hline \multirow[t]{3}{*}{7.} & Rata-rata pendapatan per bulan: & \\
\hline & a. Bidang pertanian (Rp.) & 1.001 .250 \\
\hline & b. Non pertanian (Rp.) & 2.248 .209 \\
\hline 8. & Rata-rata luas lahan sawah(Ha) & 0,5 \\
\hline 9. & Rata-rata kepemilikan ternak (Ekor) & 2 \\
\hline 10. & Rata-rata kepemilikan pohon jeruk (batang) & 6 \\
\hline 11. & Kepemilikan smartphone (\%) & 64,67 \\
\hline
\end{tabular}

Sumber: Analisis Data Primer, 2020 
Tabel 2. Menjelaskan bahwa rata-rata umur petani dalam kategori produktif yang mengindikasikan bahwa secara fisik berpeluang optimal mencurahkan waktu, tenaga, dan fikirannya untuk pengembangan usaha tani. Rata-rata petani lulus SLTP/sederajat yang mengindikasikan bahwa petani melek huruf. Mayoritas petani yang belajar di TTP Pringkuku berjenis kelamin laki-laki dan tercatat sebagai anggota kelompok tani. Lebih dari separuh umurnya petani mendedikasikan dirinya di bidang pertanian. Lama usaha tani mengindikasikan petani telah memiliki pengalaman dalam berusaha tani. Pengalaman atas apa yang dilakukannya dan pengalaman yang berasal dari orang lain. Sesuai analisa Teori Belajar Sosial yang dikemukakan Bandura (1977) dalam Hariadi (2018) bahwa perilaku petani terbentuk atas 4 proses yang berurutan. Pada awalnya petani melihat orang lain dan mengamatinya. Selanjutnya timbul minat dan petani mulai mengingat apa yang telah diamatinya. Dilanjutkan pada proses meniru perilaku orang lain dan berujung pada motivasi petani untuk berperilaku sesuai orang tersebut.

Petani yang mengakses infotek pertanian TTP Pringkuku faktanya mayoritas tidak menggantungkan sumber pendapatan di bidang pertanian. Tabel 2 menampilkan $>50 \%$ petani juga beraktifitas diluar bidang pertanian dan hasilnya pun lebih tinggi daripada hasil yang diperoleh dari usaha taninya. Hasil pertanian tergantung dari luas lahan garapan yang nyatanya tidak luas $(<1 \mathrm{Ha})$, sehingga optimalisasi usaha cenderung berhasil apabila kegiatannya dilakukan secara berkelompok. Kelompok tani merupakan salah satu pintu upaya pemberdayaan petani dan keluarganya yang bermuara pada kesejahteraan hidup. Selaras penelitian Aminah dkk, (2015) bahwa tingkat penguasaan lahan, umur, tingkat pendapatan, dan pengalaman berusaha tani berhubungan dengan keberdayaan dan memengaruhi ketahanan pangan keluarga. Selain itu kerjasama ekonomi antar anggota kelompok dengan orientasi bisnis menjadi alternatif solusi fragmentasi lahan (Rahayu, 2001).

\section{Sikap Petani Terhadap Infotek Pertanian}

Sikap petani dalam penelitian ini adalah respon atau penilaian petani berupa pernyataan terhadap informasi (teknologi budidaya padi/teknologi budidaya jeruk/teknologi budidaya sapi potong). Menurut Rosernberg dan Hovland (1960) dalam Azwar (2016), sikap terbentuk atas 3 ranah (kognitif, afektif, dan konatif). Konsep sikap diamati melalui (1) pernyataan lisan tentang perasaan yang menggambarkan ranah afektif, (2) pernyataan lisan tentang keyakinan atas pengetahuan yang mengindikasikan ranah kognitif, dan (3) pernyataan lisan tentang kecenderungan melakukan sesuatu (Chave dan Bogardus dalam Hariadi, 2011). Tabulasi sikap petani berdasarkan ranahnya ditampilkan pada Tabel 3. 
Tabel 3. Kategori Ranah Sikap Petani Terhadap Infotek Pertanian TTP Pringkuku

\begin{tabular}{|c|c|c|c|}
\hline No. & Ranah & Rata-rata Capaian (\%) & Kategori \\
\hline 1. & Kognitif & 61,63 & Setuju \\
\hline 2. & Afektif & 66,20 & Setuju \\
\hline 3. & Konatif & 51,50 & Ragu-ragu \\
\hline & Rerata & 59,96 & Ragu-ragu \\
\hline
\end{tabular}

Sumber: Analisis Data Primer, 2020

Tabel 3 menyajikan hasil analisa sikap petani terhadap informasi yang diterimanya dari TTP Pringkuku. Penilaian petani terbagi atas dua medium yaitu informasi di kebun percontohan dan website/media sosial. Ratarata capaian ranah kognitif petani menyatakan setuju terhadap infotek pertanian. Capaian ranah kognitif diperoleh dari akumulasi sikap sangat setuju petani terhadap penerapan teknologi bermanfaat untuk meningkatkan produksi tanaman/ternak dan keraguan petani terhadap penambahan biaya dan komponen teknologi yang tidak mudah tahapannya. Ratarata capaian ranah afektif menunjukkan bahwa petani senang memperoleh infotek pertanian dari kebun percontohan maupun website/media sosial TTP Pringkuku. Capaian ranah konatif berbeda dengan 2 ranah lainnya karena petani ragu-ragu untuk mencoba dan menerapkan infotek pertanian yang diterimanya. Keraguan tersebut diperkuat atas pertimbangan biaya dan kompleksitas teknologi.

Syarat inovasi teknologi pertanan idealnya menguntungkan dan proses uji cobanya mudah, sehingga harapannya petani setuju untuk menerapkan. Sesuai pendapat Rogers (1995) bahwa petani cenderung mengadopsi teknologi ketika karakteristik inovasi terpenuh. Karakteristik inovasi meliputi seperti relatif menguntungkan (relative advantage), sesuai kebutuhan/kompatibel (compatibility), sederhana/tingkat kerumitan rendah (complexity), mudah di coba (triability), dan dapat diamati (observability) serta fleksibel dan dapat ditemukan kembali (re-invention) oleh adopter.

Perbedaan capaian ranah sikap mengindikasikan bahwa petani mengalami inkonsistensi sikap yang menimbulkan disonansi kognitif. Hasil penelitian ini searah dengan penelitian Yunandar (2019) yang menggunakan istilah ambivalensi sikap untuk menunjukkan bahwa meskipun sikap generasi muda terdidik positif terhadap wirausaha pertanian, tetapi ragu-ragu untuk menjalankannya terutama di bagian hulu pertanian. Pada dasarnya sikap seseorang tidaklah mudah diubah apabila ketiga ranah konsisten memberikan respon yang sama. Perubahan pada satu ranah akan berdampak bagi ranah lainnya (Tjandra dan Siska, 2013).

Perbedaan respon antar ranah menimbulkan disonansi kognitif karena seseorang mengalami 2 pengetahuan yang berbeda dan menghasilkan ketidaknyamanan secara psikologis (Azwar, 2016). Dua pendekatan untuk mengurangi disonansi kognitif dan berujung pada konsistensi sikap ditempuh dengan (1) metode langsung melalui 
perubahan pengetahuan atau (2) metode tidak langsung melalui penghindaran dari informasi yang membuat tidak nyaman (Baron dan Branscombe (2012) dalam Alfitman (2017). Dalam penelitian ini konsistensi sikap petani dapat terwujud apabila petani terlibat aktif dalam uji coba teknologi pertanian yang dilaksanakan oleh sumber informasi. Harapannya terjadi peningkatan pengetahuan dan bersedia menerapkan informasi yang telah dipelajarinya.

Kemampuan Petani Mengakses Infotek Pertanian
Kemampuan petani memperoleh infotek pertanian penting diamati karena hasil penelitian menjelaskan bahwa petani di Kabupaten Pacitan sulit mengakses informasi pertanian (Andriyati dkk, 2011). Hadirnya TTP Pringkuku sebagai sumber informasi diharapkan dapat mengurangi kesenjangan antara masifnya hasil-hasil penelitian dengan tingkat adopsi teknologi. Peluang penerapan teknologi terbuka apabila petani mampu mencari dan memperoleh informasi sesuai yang dibutuhkan. Capaian kemampuan petani mengakses infotek pertanian ditampilkan pada Gambar 1.

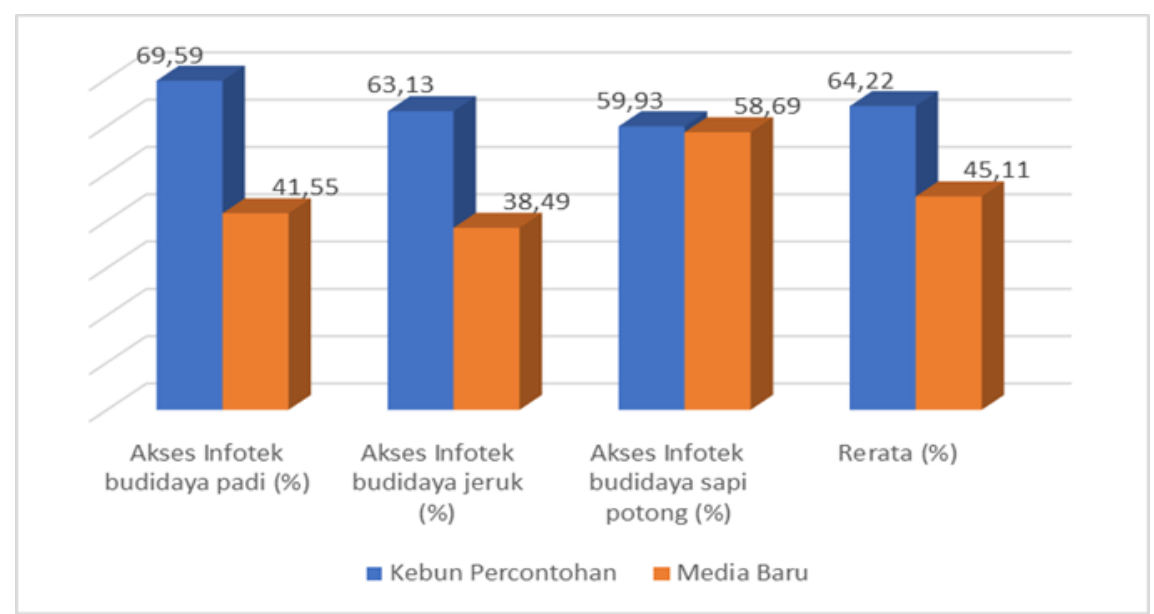

Gambar 1. Capaian Kemampuan Petani Mengakses Infotek Pertanian TTP Pringkuku

Gambar 1 menegaskan bahwa petani lebih mampu mengakses informasi di kebun percontohan dibanding melalui media baru. Dari kebun percontohan petani mampu memperoleh infotek budidaya padi dan jeruk, tetapi ragu-ragu untuk mengakses infotek budidaya sapi potong. Capaian kemampuan petani mengakses informasi melalui media baru berbeda dengan capaian kemampuan yang informasinya berasal dari kebun percontohan. Rata-rata petani menilai belum mampu mengakses infotek pertanian melalui media baru. Rendahnya kemampuan ini $(<50 \%)$ karena petani ragu-ragu mengakses infotek budidaya padi dan sapi potong serta sulit mengakses infotek budidaya jeruk melalui media baru.

\section{Pengaruh Sikap Terhadap Perilaku Akses Infotek Pertanian}

Persentase rata-rata total penilaian petani akan kemampuannya mengakses infotek pertanian baik dari kebun percontohan dan 
media baru adalah 55,08\%. Capaian tersebut menggambarkan bahwa petani ragu-ragu atau kurang mampu mengakses infotek pertanian TTP Pringkuku. Secara holistik faktor-faktor yang memengaruhi kemampuan petani mengakses informasi dapat dianalisa menggunakan Field Theory. Hariadi (2011) menjelaskan bahwa Field Theory menetapkan formula personalitas dan lingkungan adalah dua faktor yang memengaruhi seseorang melakukan sesuatu. Dalam penelitian ini analisa faktor yang memengaruhi kemampuan petani mengakses infotek pertanian lebih ditekankan pada sikap petani yang mewakili faktor personalitas. Hasil uji regresi linear sederhana ditampilkan pada Tabel 4.

Tabel 4. Hasil Uji Regresi Linear Sederhana Sikap Petani Terhadap Kemampuannya Mengakses Infotek Pertanian TTP Pringkuku

\section{Model Summary}

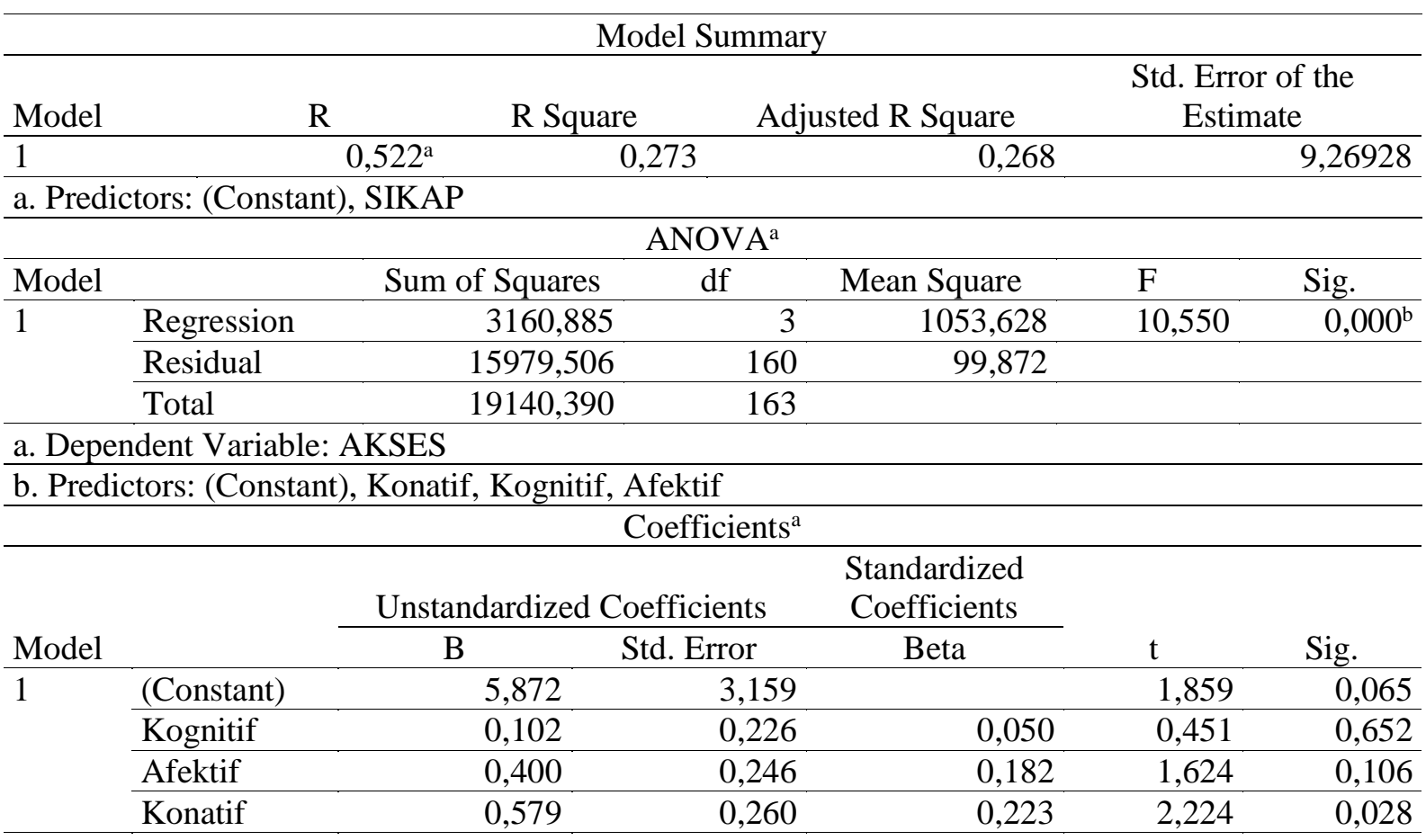

a. Dependent Variable: AKSES

Tabel 4 membuktikan variabel sikap berhubungan kuat dengan kemampuan petani mengakses infotek pertanian TTP Pringkuku. Kekuatan hubungan tersebut nampak dari nilai koefisien korelasi (R) 0,522 > 0,5. Sikap berkontribusi $27,3 \% \quad$ memengaruhi kemampuan akses informasi dan selebihnya 73,7\% dipengaruhi faktor di luar sikap. Sikap petani secara simultan berpengaruh signifikan terhadap kemampuannya mengakses infotek pertanian. Disebut signifikan karena nilai signifikansi dari uji ANOVA adalah $0,000<$ 0,05 . Bahasan yang menarik selanjutnya yaitu tentang pengaruh tiap ranah sikap terhadap kemampuan petani mengakses informasi. Hanya ranah konatif yang signifikan berpengaruh, sedangkan ranah kognitif dan afektif tidak signifikan berpengaruh. Hasil ini berbeda dengan analisa Hamrat (2018) yang membuktikan bahwa ranah kognitif dan afektif berpengaruh terhadap tingkat penerimaan 
teknologi budidaya organik, sedangkan ranah konatifnya tidak berpengaruh.

Perbedaan penelitian ini dengan penelitian terdahulu terletak pada pengaruh ranah konatif terhadap perilakunya. Penelitian ini membuktikan pentingnya derajat nilai positif pada ranah konatif yang mengindikasikan bahwa semakin petani setuju dan memiliki kecenderungan akan mencoba dan menerapkan teknologi maka akan semakin meningkatkan kemampuannya untuk mencari dan mengakses informasi yang dibutuhkan dalam usaha taninya. Strategi peningkatan ranah konatif dapat ditempuh melalui metode langsung yaitu meningkatkan keterlibatan/partisipasi petani dalam uji coba teknologi di TTP Pringkuku. Semakin intens interaksi petani belajar sosial harapannya dapat mengurangi disonansi kognitif dan berdampak pada mahirnya kemampuan petani mengakses infotek pertanian. Strategi tersebut mengacu penelitian Yunandar (2019) yang membuktikan bahwa peningkatan pengalaman diri langsung dan personalitas seseorang secara langsung meningkatkan sikapnya terhadap sesuatu.

\section{KESIMPULAN DAN SARAN}

Sikap petani ragu-ragu terhadap
informasi teknologi pertanian yang
didiseminasikan TTP Pringkuku di kebun
percontohan dan website/media sosial. Petani
mengalami inkonsistensi ranah sikap, karena
ranah kognitif dan afektif menyatakan setuju
dan senang terhadap informasi teknologi
pertanian tetapi ragu-ragu akan mencoba dan
menerapkan. Keraguan petani didasarkan pada

pertimbangan biaya dan kompleksitas teknologi pertanian. Sikap petani signifikan memengaruhi kemampuannya untuk mengakses informasi teknologi pertanian TTP Pringkuku. Semakin setuju petani terhadap informasi teknologi pertanian semakin tinggi kemampuannya untuk mengakses informasi tersebut.

\section{DAFTAR PUSTAKA}

Alfitman. (2017). Konstruk Disonansi Kognitif Dalam Penelitian Perilaku Konsumen: Apakah Popularitasnya Memang Sudah Meredup? Jurnal Ekonomi Bisnis, 22 (1), 44-57.

Aminah, S., Sumardjo, Djuara L., \& Djoko S. (2015). Strategi Peningkatan Keberdayaan Petani Kecil Menuju Ketahanan Pangan. Jurnal Sosiohumaniora, 18 (3), 253-261.

Andriyati, E., Bambang S., S., \& Endang S. (2011). Kajian Kebutuhan Informasi Teknologi Pertanian di Beberapa Kabupaten di Jawa. Jurnal Perpustakaan Pertanian, 20 (2), 30-35.

Azwar, S. (2016). Sikap Manusia Teori dan Pengukurannya Edisi Ke 2. Pustaka Pelajar: Yogyakarta.

Hamrat, M. B. (2018). Pengaruh Pengetahuan, Keterampilan dan Sikap Terhadap Tingkat Penerimaan Teknologi Budidaya Organik (Studi Kasus Petani Sayuran Organik di Kecamatan Ma'rang Kabupaten Pangkep). Tesis Universitas Hasanuddin Makassar: Makassar.

Hariadi, S. S. (2018). Petani Memahami Kearifan Lokal Petani Tradisional "Samin" dan Petani Modern. Kanisius (anggota IKAPI) Yogyakarta: Yogyakarta.

Hariadi, S. S. (2011). Dinamika Kelompok Teori dan Aplikasinya untuk Analisis Keberhasilan Kelompok Tani sebagai Unit Belajar, Kerjasama, Produksi, dan Bisnis. Sekolah Pascasarjana Universitas Gadjah Mada: Yogyakarta. 
Mulyandari, R. S. H., Sri Hery S., Sulusi P., Asmawati, Moch Takdir M., Chandra I., Priyatna S., Agung P., Edi Husen, Ridwan R., Eko Sri M., Syafaruddin., Endang R., \& Henriyadi. (2016). Pedoman Umum Pembangunan dan Pengembangan Taman Sains dan Teknologi Pertanian (TSTP) Edisi 2016. Kementerian Pertanian: Jakarta.

Rahayu, R. I. (2018). Corporate Farming Sebagai Solusi Fregmentasi Lahan Pertanian di Indonesia: https://agricsoc.faperta.ugm.ac.id/2018/0 9/16/corporate-farming-sebagai-solusifragmentasi-lahan-pertanian-diindonesia/. Diakses pada tanggal 8 November 2020.

Rogers, E., M. (1995). Diffusion of Innovations Fourth Edition. The Free Press: New York.

Saywqi, A. (2017). Perilaku Pencarian Informasi Guru Besar Universitas Islam Negeri Antasari Banjarmasin. Jurnal Ilmu Perpustakaan dan Informasi, 1 (1), 19-44.

Tjandra, E. A., \& Siska R. T. (2013). Hubungan Antara Komponen Kognitif, Komponen Afektif dan Komponen Perilaku Terhadap Konsumen Memanfaatkan Teknologi Internet. Jurnal Manajemen, 17 (1), 42-52.

Yunandar, D. T. (2019). Pengalaman Diri Langsung Dalam Model Pembentukan Sikap Generasi Muda Terdidik Terhadap Wirausaha Di Sektor Pertanian. Disertasi Universitas Gadjah Mada: Yogyakarta. 